\title{
Corrosion Behavior of Carbon Steels in CCTS Environment
}

\author{
M. Cabrini, S. Lorenzi, and T. Pastore \\ Department of Engineering and Applied Sciences, University of Bergamo, Viale Marconi 5, Dalmine, 24044 Bergamo, Italy \\ Correspondence should be addressed to S. Lorenzi; sergio.lorenzi@unibg.it
}

Received 17 November 2015; Accepted 11 January 2016

Academic Editor: Ksenija Babic

Copyright (C) 2016 M. Cabrini et al. This is an open access article distributed under the Creative Commons Attribution License, which permits unrestricted use, distribution, and reproduction in any medium, provided the original work is properly cited.

\begin{abstract}
The paper reports the results of an experimental work on the effect of steel microstructures on morphology and protectiveness of the corrosion scale formed in water saturated by supercritical $\mathrm{CO}_{2}$. Two HSLA steels were tested. The microstructures were modified by means of different heat treatments. Weight loss was measured after exposure at $\mathrm{CO}_{2}$ partial pressure of 80 bar and $60^{\circ} \mathrm{C}$ temperature. The morphology of the scale was analyzed by means of scanning electron microscope (SEM) energy-dispersive $\mathrm{X}$-ray spectroscopy (EDX). Cathodic potentiodynamic tests were carried out on precorroded specimens for evaluating the effect of preformed scales on cathodic polarization curves in $\mathrm{CO}_{2}$ saturated sulphuric acid solution at $\mathrm{pH} 3$, which is the value estimated for water saturated by supercritical $\mathrm{CO}_{2}$. The results are discussed in order to evaluate the effect of iron carbide network on scale growth and corrosion rate. Weight loss tests evidenced average corrosion rate values in the range $1-2.5 \mathrm{~mm} / \mathrm{y}$ after 150 -hour exposure. The presence of thick siderite scale significantly reduces the corrosion rate of carbon steel. A slight decrease of the corrosion rate was observed as the scale thickness increases and moving from martensite to microstructures containing carbides.
\end{abstract}

\section{Introduction}

Environmental pollution, produced by industrial and civil activities, represents one of the most serious problems for climatic changes and human health. Combustion processes of fossil fuels contribute to the atmospheric level of carbon dioxide that is the most important one of the greenhouse gases, largely responsible for the "enhanced greenhouse effect."

CCTS (Carbon Capture, Transport, and Storage) technologies for capturing waste $\mathrm{CO}_{2}$ from combustion gases of fossil fuels used for the production of energy, its compression and liquefaction, transport in pipelines, and storage in the deep underground sites become increasingly important. Despite the significant ecological benefits, there are still unsolved issues, mainly related to economics and risks of accidental release into the atmosphere of large amounts of $\mathrm{CO}_{2}$. Plant reliability requires accurate material selection and a deep knowledge of material corrosion in the presence of very high pressure of wet $\mathrm{CO}_{2}$. The transport in supercritical conditions will be necessarily carried out by means of existing carbon steel pipelines to reduce and maximize the amount of the mass flux [1].

Although dry carbon dioxide is not aggressive for carbon steel, the presence of water and other pollutants can stimulate corrosion [2]. The $\mathrm{CO}_{2}$ corrosion, usually named sweet corrosion, occurs by hydration of $\mathrm{CO}_{2}$ to carbonic acid in the aqueous phase. It has widely been studied in the Oil and Gas industry in which considerable amount of data were collected from plants, at $\mathrm{CO}_{2}$ partial pressures up to 10 bar.

The role of steel microstructure on the sweet corrosion can mostly be ascribed to the formation and quality of protective corrosion scales. However, such effect has not widely been studied in CCTS systems. Supercritical $\mathrm{CO}_{2}$ partial pressures cause very high corrosion rates in early exposure but supersaturation conditions for precipitating the protective scale are more easily reached, owing to the high concentration of carbonate species. Compared to the large number of literature works on sweet corrosion in Oil and Gas, only few works are devoted to the supercritical conditions, above 73.9 bar and $31^{\circ} \mathrm{C}$ [3-8]. Steel microstructure plays an important role on corrosion scale adhesion. In ferriticpearlitic steels, the selective attack of ferrite grain due to the galvanic coupling between ferrite and $\mathrm{Fe}_{3} \mathrm{C}$ and the consequent internal acidification [9] leaves steel behind a network of iron carbides that can act as reinforcement into the film and enhance the adhesion on substrate. Thus, the presence and morphology of carbide phase (i.e., size and distribution) in the scale may be crucial [9]. 
The aim of the work is the study of the corrosion scale morphology on steel with different microstructures, covering coarse ferrite-pearlite, fine ferrite-pearlite, martensite, and tempered martensite, by means of scanning electron microscope (SEM) energy-dispersive X-ray spectroscopy (EDX). Cathodic potentiodynamic tests were carried out on precorroded specimens for evaluating the effect of preformed scales on cathodic polarization curves in $\mathrm{CO}_{2}$ saturated sulphuric acid solution at $\mathrm{pH}$ equal to that estimated in the literature for water saturated with supercritical $\mathrm{CO}_{2}$.

\section{Experimental}

2.1. Material and Specimens. The steel chemical compositions are reported in Table 1 and microstructures are shown in Figure 1. Steel A is a hot rolled API 5L grade X65 with a banded microstructure containing ferrite and pearlite whereas Steel B is not standard grade microalloyed HSLA steel. The microstructure of Steel B was modified by means of five different heat treatments: annealing for 2 hours at $950^{\circ} \mathrm{C}(\mathrm{A})$, normalization (N), water quenching (WQ), water quenching and tempering for 1.5 hours at $350^{\circ} \mathrm{C}$ (WQ-T1), and water quenching and tempering for 1.5 hours at $600^{\circ} \mathrm{C}$ (WQ-T2).

After heat treatment, disks (Ø $20 \mathrm{~mm} \times 2 \mathrm{~mm}$ ) for weight loss and electrochemical tests were machined from heattreated bars. Steel A was tested only in as-received conditions (sample A). Steel B samples are indicated with the letter $\mathrm{B}$ followed by the heat treatment. The microstructures and Vickers hardness are summarized in Table 2 and Figure 2.

2.2. Tests in Autoclave. The tests were performed at $60^{\circ} \mathrm{C}$ $\left( \pm 1^{\circ} \mathrm{C}\right), 80$ bar $\mathrm{CO}_{2}$ partial pressure for 150 hours.

Before exposure, the specimens were grinded with silicon carbide emery paper up to 1000 grit and then cleaned with acetone in ultrasonic bath. A PTFE shaft was used to grant electrical insulation between the specimens and the holder. The specimen holder was placed in a $6 \mathrm{~L}$ autoclave filled with about $4 \mathrm{~L}$ distilled water. All the specimens with different heat treatments (12 specimens) were fully dipped into water. Several pressurization and depressurization cycles with nitrogen were carried out after specimens immersion to achieve oxygen contents well below $0.2 \mathrm{ppm}$. Low pressure (about 2 bar) $\mathrm{CO}_{2}$ pressurization and depressurization cycles were executed for stripping nitrogen from the solution. The autoclave was then heated up to $60^{\circ} \mathrm{C}$ and, finally, it was pressurized with $\mathrm{CO}_{2} \cdot \mathrm{CO}_{2}$ was directly pumped inside the autoclave by means of a gas-booster equipped with a preheater regulated at $40^{\circ} \mathrm{C}$ in order to directly achieve supercritical condition.

2.3. Corrosion Tests. The specimens for both weight loss tests and potentiodynamic tests were $15 \mathrm{~mm}$ diameter and $5 \mathrm{~mm}$ height cylinders. X-ray analysis specimens were of $50 \mathrm{~mm}$ diameter and $5 \mathrm{~mm}$ height. At least four specimens for each condition were immersed. Half of the specimens were used for weight loss tests and the others were used for the cathodic potentiodynamic tests. After the X-ray analysis, SEM observation has been performed to evaluate the corrosion
TABLE 1: Chemical composition of steels.

\begin{tabular}{lcccccccc}
\hline Steel & $\mathrm{C}$ & $\mathrm{Mn}$ & $\mathrm{Si}$ & $\mathrm{P}$ & $\mathrm{S}$ & $\mathrm{Ni}$ & $\mathrm{Cr}$ & $\mathrm{Mo}$ \\
\hline $\mathrm{A}$ & 0.27 & 0.70 & 0.32 & 0.02 & 0.04 & 0.10 & 0.10 & 0.09 \\
$\mathrm{~B}$ & 0.06 & 1.94 & 0.30 & 0.01 & - & 0.29 & 0.04 & 0.25 \\
\hline
\end{tabular}

scale morphology. SEM observations have been also carried out on metallographic sections grinded with emery paper and polished up to $1 \mu \mathrm{m}$ with diamond paste. Nital $2 \%$ metallographic etching was considered to evidence microstructure.

Corrosion rate was evaluated by weight loss measurements after pickling in $6 \mathrm{~N}$ hydrochloric acid inhibited with $3 \mathrm{~g} / \mathrm{L}$ hexamethylenetetramine at $60^{\circ} \mathrm{C}$ for 1 minute. The weight loss data were corrected according to ASTM G1 standard to take into account about the bare metal removal due to pickling.

Cathodic Potentiodynamic Tests. Potentiodynamic tests were performed on disk specimens after exposure in supercritical $\mathrm{CO}_{2}$ saturated water. The specimens were rapidly dried and stored in order to maintain the scale. The electrochemical tests were performed in one-liter ASTM G5 standard cell by using a sample holder with exposed area of $1 \mathrm{~cm}^{2}$, a standard calomel reference electrode (SCE), and two graphite counter electrodes. Before tests, the open circuit potential was monitored for 30 minutes. The tests were performed at room temperature in $\mathrm{H}_{2} \mathrm{SO}_{4}$ diluted solution $\left(10^{-3} \mathrm{Mole} / \mathrm{L}\right)$ saturated with flowing $\mathrm{CO}_{2}$ at $1 \mathrm{bar}(\mathrm{pH} 3)$. The free corrosion potential was measured for 300 seconds after the immersion of specimens. The tests were carried out at $10 \mathrm{mV} /$ minute scan rate from free corrosion potential $\left(E_{\text {cor }}\right)$ to $0.50 \mathrm{~V}$ of cathodic polarization. The curves were modified to take into account about the ohmic drop in the electrolyte and into the scale by means of electrochemical impedance spectroscopy measurements at high frequency $\left(10^{3}-10^{4} \mathrm{~Hz}\right)$.

\section{Results}

3.1. Corrosion Rate. Table 3 reports the corrosion rates after autoclave tests. The mean value was calculated on two specimens for Steel B. The standard deviation was about $0.02 \mathrm{~mm} / \mathrm{y}$ for Steel A specimens. The corrosion rate is about $2 \mathrm{~mm} / \mathrm{y}$ and slightly increases from ferritic-pearlitic to martensitic microstructures.

3.2. Morphologies. At the end of the exposure, all the specimens are totally covered by a thick scale of siderite (Figure 2) confirmed by XRD spectra (Figure 3 ). The high thickness masked the X-ray peaks of ferrite, pearlite, and martensite of steel substrate. Two or more layers of iron carbonate crystals of different dimension compose the scale.

Figure 4 shows the aspect of the scale formed on Steel $A$ as a function of the ferrite-pearlite bands orientation. Corrosion attack penetrates inside the steel following preferential path along pearlite islands if the bands are oriented perpendicularly to the exposed area. The film mainly grows towards the steel and large cavities can be noticed between the ferrite bands. With the pearlite bands parallel to the 

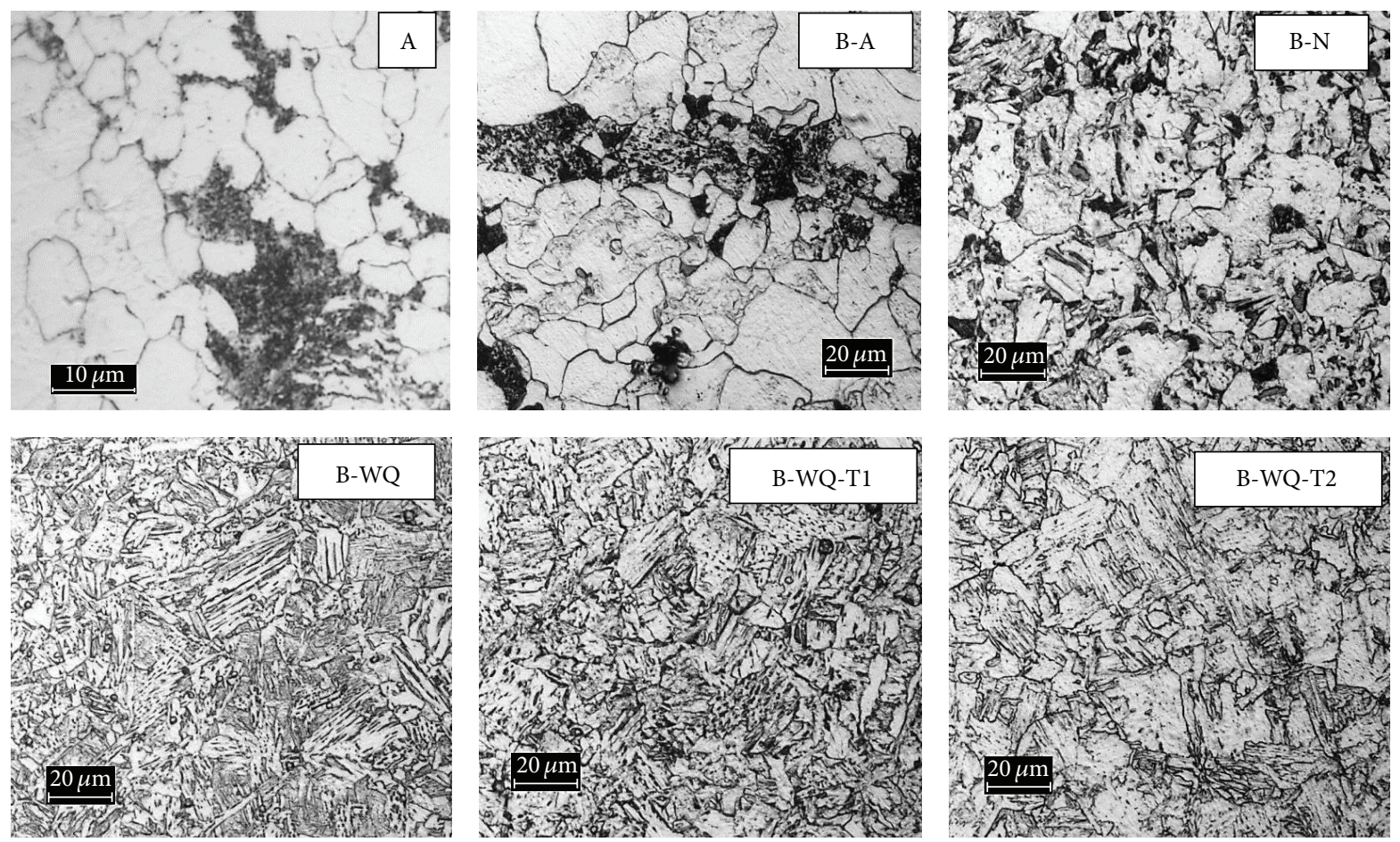

Figure 1: Microstructures of steels (Nital 2 etching).

TABLE 2: Heat treatments and microstructure of the tested steels.

\begin{tabular}{lccc}
\hline Steel & Heat treatment & Microstructure & HV \\
\hline A & Hot rolling & Ferrite-pearlite & 170 \\
B-A & Annealing & Coarse ferrite-pearlite & 135 \\
B-N & Normalizing & Ferrite-pearlite & 196 \\
B-WQ & Water quenching (WQ) & Martensite & 270 \\
B-WQ-T1 & WQ and tempering at $350^{\circ} \mathrm{C}$ & Low-temperature-tempered martensite & 245 \\
B-WQ-T2 & WQ and tempering at $600^{\circ} \mathrm{C}$ & Fully tempered martensite & 230 \\
\hline
\end{tabular}

TABLE 3: Average corrosion rates (CR) from weight loss measurement and scale thickness.

\begin{tabular}{lcccccc}
\hline Sample & A & B-A & B-N & B-WQ & B-WQ-T1 & B-WQ-T2 \\
\hline $\begin{array}{l}\text { CR (mm/a) } \\
\begin{array}{l}\text { Scale } \\
\text { thickness } \\
(\mu \mathrm{m})\end{array}\end{array}$ & 2.35 & 1.89 & 1.86 & 2.18 & 2.11 & 1.87 \\
\hline
\end{tabular}

exposed surface, the morphology shows large discontinuities, which assume an elongated shape and tend to detach the scale. The corrosion rate reaches the highest level (Table 3). Similar behavior was evidenced on B-A specimens (Figure 5). However, it should be underlined that the dimension of the bands is lower than Steel A due to the very low carbon content. Moreover, the scale was less porous on the $\mathrm{B}-\mathrm{N}$ specimens, which have more fine perlite microstructure and much less evident bands (Figure 6).

Pearlite is not present in quenched steels (B-WQ) and anisotropy of microstructure with respect to the rolling direction was eliminated by the heat treatment. The scale is less porous (Figure 7) but the corrosion attack propagates along the martensite laths and undissolved martensite is incorporated in the scale. This effect is more pronounced for the full martensitic specimens (B-WQ). In this last case, the scale is thinner than the ferritic-pearlitic samples, and slightly higher corrosion rate was observed.

3.3. Cathodic Potentiodynamic Tests. The potentiodynamic tests were carried out in dilute sulfuric acid saturated with $\mathrm{CO}_{2}$ at $\mathrm{pH} 3$ as suggested by Sim et al. [10] to evidence the shielding effect of the scale on the cathodic process.

Figure 8 shows the potentiodynamic curves of the steels. All bare specimens, regardless of steel or heat treatment, showed coincident curves with hydrogen limiting current density around $3 \cdot 10^{-4} \mathrm{~A} / \mathrm{cm}^{2}$. The scales produce two main variations. It decreases hydrogen diffusion limiting current density more than two order magnitudes and rises corrosion potential. The systematic increasing of free corrosion potentials denotes an effect of the scale that is more accentuated on anodic curve than cathodic curves. 


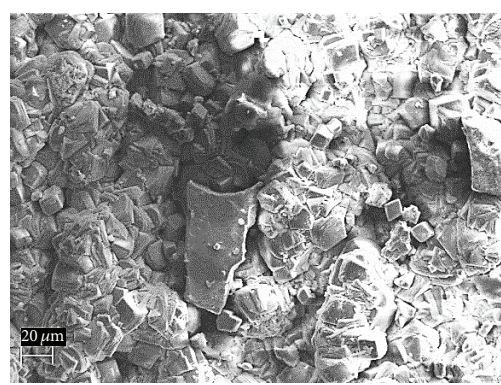

(a)

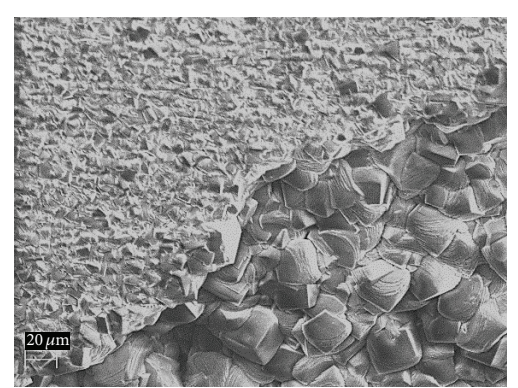

(b)

FIGURE 2: SEM image of scale after exposure in autoclave: (a) B-N specimen, (b) B-WQ specimen.

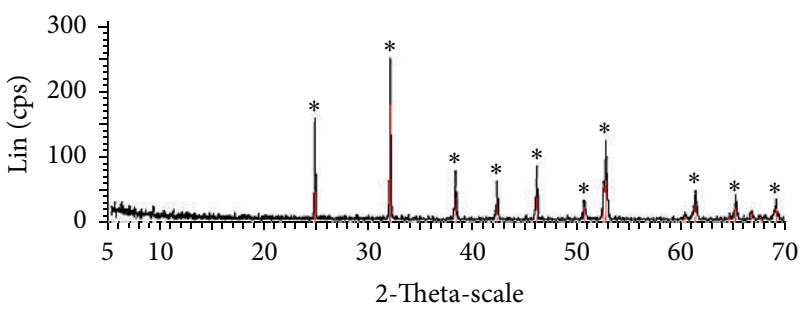

FIGURE 3: XRD spectra of scale on specimens B-A and B-WQ.

\section{Discussion}

4.1. Corrosion Mechanism. The corrosion of carbon steel in the presence of $\mathrm{CO}_{2}$ involves the anodic oxidation of iron to ferrous ions (1) and the cathodic process of hydrogen evolution (2):

$$
\begin{aligned}
\mathrm{Fe} & \longrightarrow \mathrm{Fe}^{2+}+2 \mathrm{e}^{-} \\
2 \mathrm{H}^{+}+2 \mathrm{e}^{-} & \longrightarrow \mathrm{H}_{2}
\end{aligned}
$$

The corrosivity of $\mathrm{CO}_{2}$ derives from the chemical reaction of hydration of $\mathrm{CO}_{2}$ in the electrolyte to carbonic acid (3) and its dissociation $((4)$ and (5)) that produces hydrogen ions and from the direct reduction of carbonic acid (6) [11]:

$$
\begin{aligned}
\mathrm{CO}_{2}+\mathrm{H}_{2} \mathrm{O} & \rightleftarrows \mathrm{H}_{2} \mathrm{CO}_{3} \\
\mathrm{H}_{2} \mathrm{CO}_{3} & \rightleftarrows \mathrm{HCO}_{3}{ }^{-}+\mathrm{H}^{+} \\
\mathrm{HCO}_{3}{ }^{-} & \rightleftarrows \mathrm{CO}_{3}{ }^{2-}+\mathrm{H}^{+} \\
2 \mathrm{H}_{2} \mathrm{CO}_{3}+2 \mathrm{e}^{-} & \longrightarrow \mathrm{H}_{2}+2 \mathrm{HCO}_{3}^{-}
\end{aligned}
$$

The reduction of carbonic acid becomes important at $\mathrm{pH}>5$. The local alkalization due to $\mathrm{H}^{+}$consumption increases the concentration of dissociated species of $\mathrm{CO}_{2}$.

The corrosion rate after 24-hour exposure is in the range from 10 to $28 \mathrm{~mm} /$ years, as reported by Nešić and Lee, Cui et al. [12], and Cabrini et al. [13, 14]. The corrosion rates observed in this work are very lower than these values, owing to the long exposure time that promotes the formation of a protective scale of siderite according to reaction (7) [15]:

$$
\mathrm{Fe}^{2+}+\mathrm{CO}_{3}^{2-} \rightleftarrows \mathrm{FeCO}_{3}
$$

The reduction of an order of magnitude of the corrosion rate of the specimens was also observed in previous works for exposure time higher than 150 hours, $\mathrm{CO}_{2}$ partial pressure ranging from 40 to $135 \mathrm{bar}$, and $60^{\circ} \mathrm{C}$ temperature $[13,14]$.

4.2. Scale Precipitation. The morphologies of the scale after the exposure in autoclave show a composite nature with inner layer of big crystals of siderite and external layer of very small crystals (Figure 2) due to variation of the precipitation mechanism with buildup of corrosion product in the solution.

The precipitation of the scale occurs when the concentrations of ferrous and carbonate ions exceed the solubility product, which is function of temperature and ionic strength [16]. Exposure time promotes the scale formation because the concentration of $\mathrm{Fe}^{2+}$ ions inside the solution quickly increases due to very high initial corrosion rates. In addition, a high volume of gas in equilibrium with the solution grants the supply of the carbonate species depleted by the cathodic reaction.

The conditions at metal/solution interface are quite different from the bulk solution due to active steel corrosion. The limit of solubility is easily reached very close to the metal surface and scale begins to precipitate. Several authors emphasize the importance of cathodic species diffusion from the bulk solution to the metal surface and vice versa, the reaction products from the interface to the bulk solution, to achieve the conditions that favor iron carbonate precipitation $[11,15,16]$.

As the steel corrodes, the concentration of $\mathrm{Fe}^{2+}$ in solution increases and a decrease of the diffusion rate of these ions from the reaction interface to the bulk solution occurs. The diffusion rate of $\mathrm{CO}_{3}{ }^{2-} / \mathrm{HCO}_{3}{ }^{-}$ions produced by the cathodic reaction also decreases to preserve electroneutrality at the interface. Therefore, the precipitation of the siderite can take place at $\mathrm{Fe}^{2+}$ ion concentration lower than supersaturation of the bulk solution, but the corrosion products layer is stable only in the case of continuous $\mathrm{Fe}^{2+}$ ions supply by corrosion.

The siderite crystals nucleation rate is high and does not affect the film formation: during their growth on the steel surface to the bulk solution, they tend to form a continuous but very porous film. The balance between the consumption of 

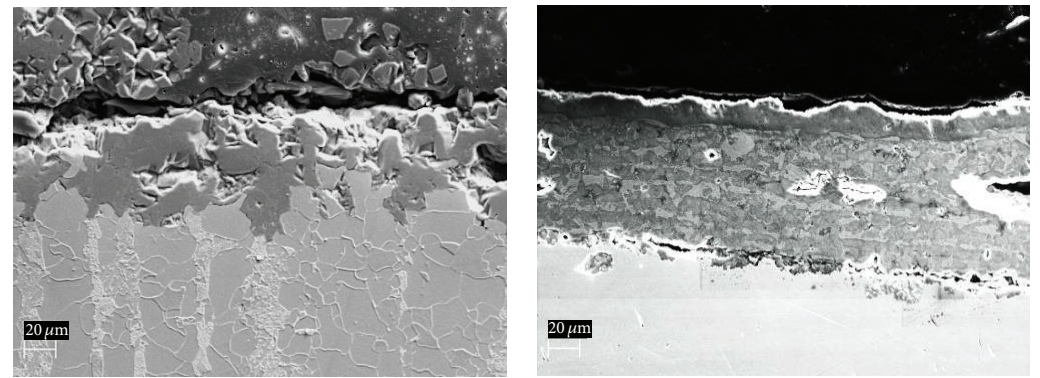

FIGURE 4: Image of the scale on surfaces of specimen A with different ferrite-pearlite bands orientation.
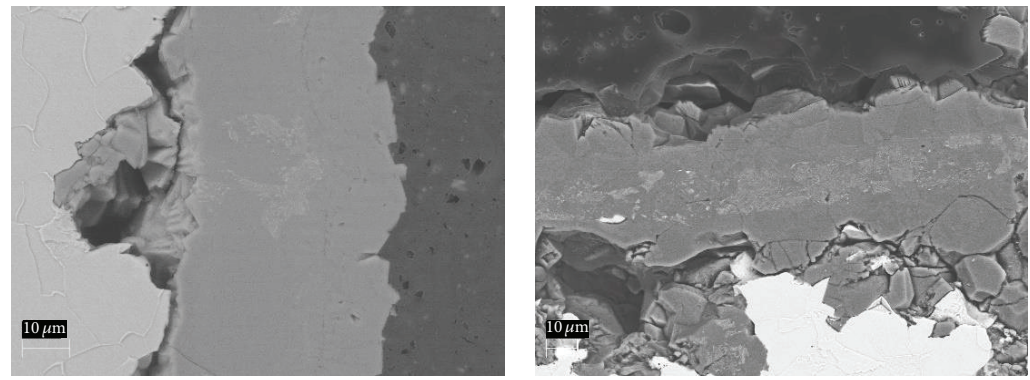

FIGURE 5: Carbide bands in the scale of B-A specimens.

ferrous ions and their production will maintain the supersaturation conditions at metal/scale interface that are necessary to stimulate the siderite crystal growth. The $\mathrm{H}^{+}$consumption due to the cathodic reaction promotes the dissociation of carbonic acid, moving the equilibrium of $\mathrm{CO}_{2}$ hydration and dissociation to the right. The corrosion rate decreases as the scale grows and so the ions concentration falls below the supersaturation conditions, promoting the protective film dissolution and increasing the $\mathrm{Fe}^{2+}$ concentration in the bulk solution.

Afterwards, once oversaturation conditions are achieved at the scale-solution interface, the scale can also grow for direct reprecipitation from bulk solution.

When supersaturation conditions are reached in the bulk solution, small crystals of siderite precipitate on the outer surface of the scale and seal the porosity.

Choi and Nešić [7] report a model for estimating mutual solubilities of $\mathrm{CO}_{2}$ and water in the two coexisting phases and calculating the concentration of corrosive species in the free water at various pressure and temperatures. Based on this model, the content of carbonic acid, bicarbonate, and carbonate ions at 80 bar $\mathrm{CO}_{2}$ partial pressure and $60^{\circ} \mathrm{C}$ can be assumed equal to $2-2.5,0.6-0.7$, and $7-7.5 \cdot 10^{-8} \mathrm{mmole} / \mathrm{L}$, respectively, with $\mathrm{pH}$ in the range $3.1-3.2$. Solubility product of iron carbonate is equal to $8.24 \cdot 10^{-13}$ at $60^{\circ} \mathrm{C}$ according to Braun [17]. The limit for iron carbonate precipitation can be calculated by considering solubility product of iron carbonate and on the concentrations evaluated by the model of Choi and Nešić, through the following relation:

$$
K_{\mathrm{SeCO}_{3}}=\frac{\left[\mathrm{Fe}^{2+}\right] \cdot\left[\mathrm{CO}_{3}{ }^{2-}\right]}{\left[\mathrm{FeCO}_{3}\right]}
$$

For the testing conditions assumed in this work, the precipitation begins once $\mathrm{Fe}^{2+}$ ions concentration exceeds 11 mmole/L.

Considering an autoclave volume of 4 liters and the total exposed area of the specimens equal to about $10 \mathrm{~cm}^{2}$, this concentration is reached in about 136 hours at $20 \mathrm{~mm} /$ years constant corrosion rate, which is compatible with the time required for the formation of the scale.

Actually, tests carried out at short time exposure showed the presence of noncontinuous carbonate scale probably due to the fact that corrosion rate just after immersion on bare steel is higher than the mean value measured at 24 -hour exposure $[13,14]$.

4.3. Effect of the Scale on Polarization Curve of Steel in Acid Solution. Increasing of the corrosion potential due to the presence of the scale was observed in the potentiodynamic tests (Figure 8 ). The siderite scale is not conductive and acts as a barrier that covers the metal surface, while cementite can act as cathode. Nešić et al. reported that the main effect of protective iron carbonate films in $\mathrm{CO}_{2}$ corrosion is to cover the metal surface and make it unavailable for corrosion rather than act as an effective diffusion barrier [16].

A pure shielding effect should not affect the corrosion potential because both anodic and cathodic areas decrease. Furthermore, a reduction of diffusion transport of hydrogen ion, which reduces the hydrogen limiting current, tends to decrease the free corrosion potential and not to increase it.

The systematic increasing of free corrosion potentials during potentiodynamic test in acid solution indicates that there is an effect of the scale on anodic curves. Han et al. [18] studied the electrochemical behavior of steel in the presence of $\mathrm{CO}_{2}, \mathrm{HCO}_{3}{ }^{-}$, or carbonate ions, founding a sort of pseudopassivation strictly dependent upon the $\mathrm{pH}$ : 

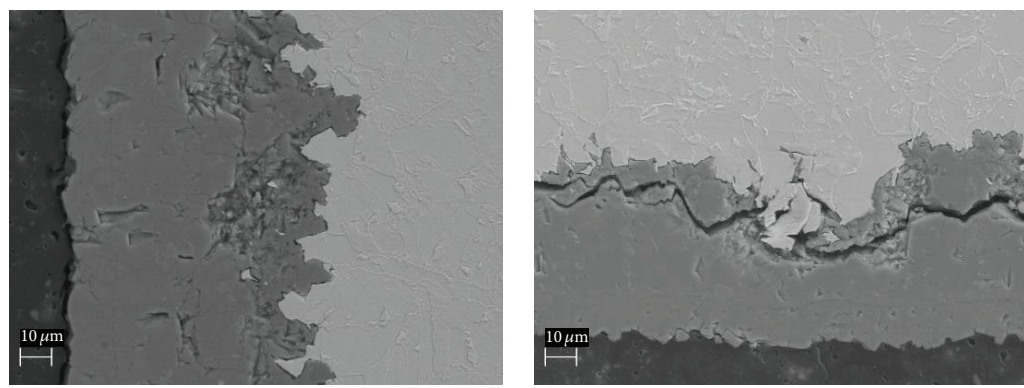

Figure 6: Scale morphology on B-N specimens.
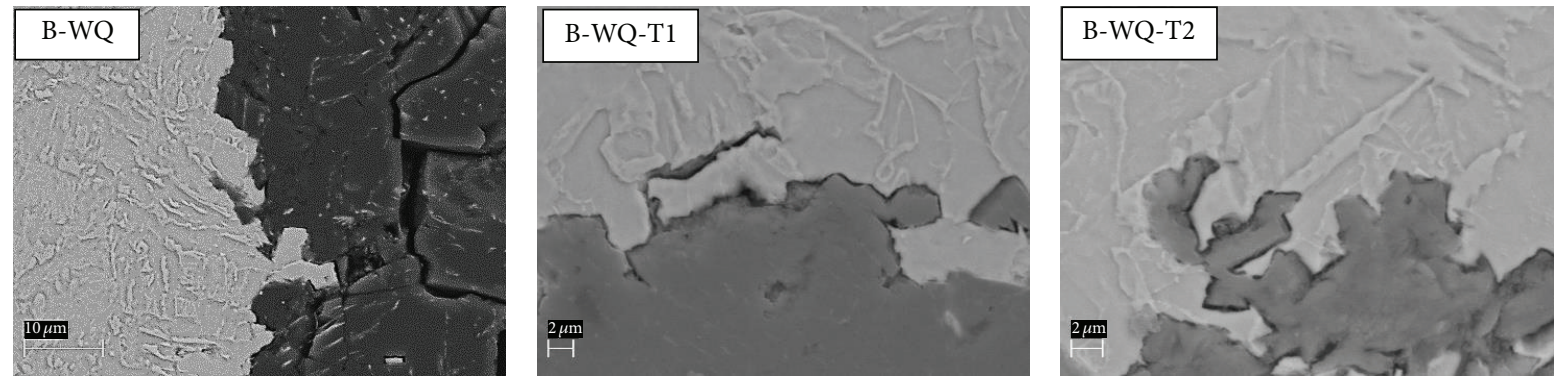

FIGURE 7: Scale morphology on quenched and tempered steels.

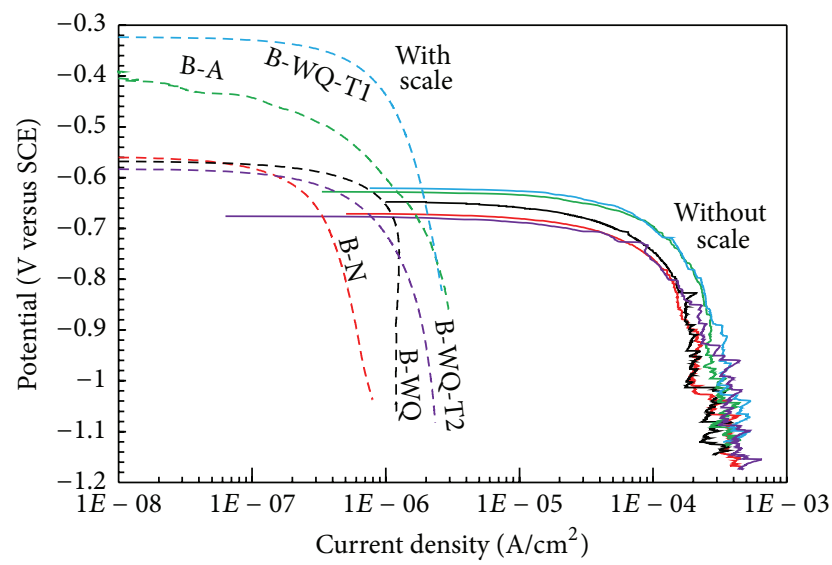

FIGURE 8: Effect of scale formed in autoclave test in supercritical $\mathrm{CO}_{2}$ on cathodic potentiodynamic curve in sulphuric acid solution at $\mathrm{pH} 3$.

the higher the $\mathrm{pH}$, the higher the protectiveness of $\mathrm{FeCO}_{3}$ layer and pseudopassivation. Significant increase in open circuit potential and a decrease of the corrosion rate were observed at $\mathrm{pH} 8$, owing to the formation of a mixed film of $\mathrm{FeCO}_{3}$ and magnetite $\left(\mathrm{Fe}_{3} \mathrm{O}_{4}\right)$. Li et al. reported that the pseudopassivation could not be achieved at $\mathrm{pH} 5.6$ [19]. At $\mathrm{pH} 3$, the scale is mainly constituted by siderite, which does not promote a passive or pseudopassive state.

The increase of the corrosion potential could be ascribed to iron ion concentrations on metal surface in the scale higher than bare metal, producing high overvoltage of anodic process. On surface without any scale, the fast cathodic process (Figure 8 ) induces hydrogen evolution that stirs the diffusion layer and reduces the accumulation of iron ions at the metal solution surface.

However, it was noted that the martensitic samples showed the lowest increases of the corrosion potential in the presence of the scale and the sample with microstructures containing carbide was characterized by the highest increases of corrosion potential. Cathodic reaction could also take place on carbides inside the scale, especially on continuous carbides networks. Such a conductivity counteracts the barrier effect on cathodic process.

4.4. Effect of Steel Microstructure. The role of cementite in the scale formation is complex. Crolet et al. [9] hypothesized a corrosion mechanism based on the local galvanic couple between ferrite and cementite and the action of pearlite favors on scale stability. Nešić et al. evidence that the film protectiveness depends on the porosity more than the scale thickness [16].

Figure 9 shows the variation of corrosion rate as a function of average thickness of scale and steel microstructure. The corrosion rate decreases by $20 \%$ moving from specimens without any carbides to microstructure containing carbides and from scale thickness of about 40 micrometers to 80 micrometers. However, it must be outlined that the results were obtained on steel with very low carbon content.

\section{Conclusion}

The paper reports the results of electrochemical and weight loss test on steels with different microstructures exposed to CCTS environment. The analysis of the morphology of corrosion scales is also presented. Weight loss tests evidenced average corrosion rate values in the range $1-2.5 \mathrm{~mm} / \mathrm{y}$ after 


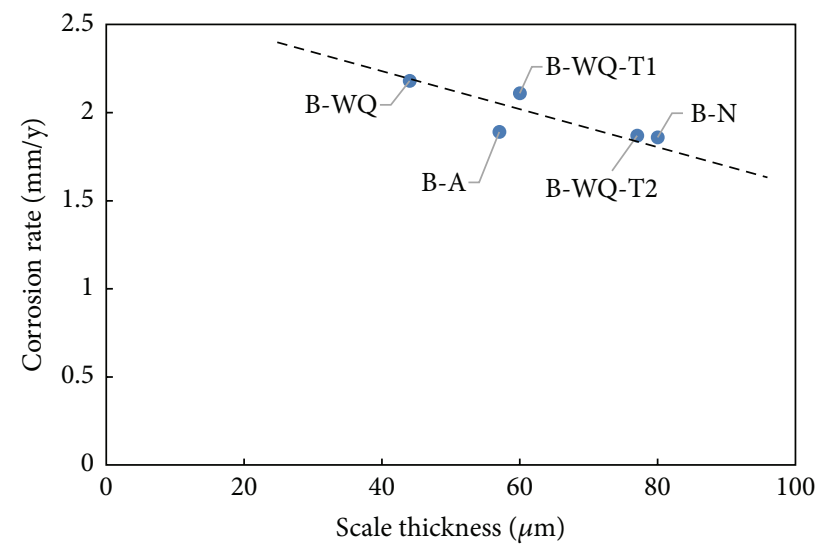

FIGURE 9: Correlation between corrosion rate and average scale thickness.

150-hour exposure. The values agree with the literature data and are significantly lower than expected in the absence of protective scale. All the specimens evidenced the presence of thick scale of corrosion products that significantly reduces the corrosion rate of carbon steel. Great siderite crystals, at the steel-scale interface, and fine crystals, at the scale/solution interface, composed the scale. Fine crystals partially seal the scale porosities, reducing corrosion rate.

Potentiodynamic cathodic curves in sulphuric acid on precorroded specimens covered by the scaled form during test in autoclave evidenced a reduction of the hydrogen limiting current and an increase of corrosion potential in the presence of the scale for all the microstructures. A slight decrease of the corrosion rate was observed as the scale thickness increases and moving from martensite to microstructures containing carbides.

\section{Conflict of Interests}

The authors declare that there is no conflict of interests regarding the publication of this paper.

\section{Acknowledgment}

This research was financed by Italy ${ }^{\bullet}$ Project of University of Bergamo.

\section{References}

[1] F. Edelvik, B. Graver, L. Torbergsen, and O. Saugerud, "Development of a guideline for safe, reliable and cost efficient transmission of $\mathrm{CO}_{2}$ in pipelines," Energy Procedia, vol. 1, no. 1, pp. 1579-1580, 2009.

[2] B. Sass, H. Farzan, R. Prabhakar et al., "Considerations for treating impurities in oxy-combustion flue gas prior to sequestration," Energy Procedia, vol. 1, no. 1, pp. 535-542, 2009.

[3] M. Seiersten, "Corrosion of pipeline steels in supercritical $\mathrm{CO}_{2} /$ water mixtures," in Proceedings of the European Corrosion Congress (EUROCORR '00), London, UK, September 2000.

[4] M. Seiersten, "Materials selection for separation, transportation and disposal of $\mathrm{CO}_{2}$," in Proceedings of the CORROSION, Paper no. 01042, NACE International, Houston, Tex, USA, March 2001.

[5] S. Hesjevik, S. Holsen, and M. Seiersten, "Corrosion at high $\mathrm{CO}_{2}$ pressure," Paper 03345, CORROSION, NACE, Houston, Tex, USA, 2003.

[6] Y.-S. Choi and S. Nešić, "Corrosion behavior of carbon steel in supercritical $\mathrm{CO}_{2}$-water environments," in Proceedings of the CORROSION, Paper no. 09256, NACE International, Atlanta, Ga, USA, March 2009.

[7] Y.-S. Choi and S. Nešić, "Determining the corrosive potential of $\mathrm{CO}_{2}$ transport pipeline in high $\mathrm{pCO}_{2}$-water environments," International Journal of Greenhouse Gas Control, vol. 5, no. 4, pp. 788-797, 2011.

[8] F. Ayello, K. Evans, R. Thodla, and N. Sridhar, "Effect of impurities on corrosion of steel in supercritical $\mathrm{CO}_{2}$," in Proceedings of the CORROSION, Paper no. 10193, NACE International, San Antonio, Tex, USA, March 2010.

[9] J. L. Crolet, N. Thevenot, and S. Nesic, "Role of conductive corrosion products in the protectiveness of corrosion layers," Corrosion, vol. 54, no. 3, pp. 194-203, 1998.

[10] S. Sim, P. Corrigan, I. Cole, and N. Birbilis, "Use of aqueous solutions to simulate supercritical $\mathrm{CO}_{2}$ corrosion," Corrosion, vol. 68, no. 4, pp. 045004-1-045004-11, 2012.

[11] M. Nordsveen, S. Nešić, R. Nyborg, and A. Stangeland, "A mechanistic model for carbon dioxide corrosion of mild steel in the presence of protective iron carbonate films-part 1: theory and verification," Corrosion, vol. 59, no. 5, pp. 443-456, 2003.

[12] Z. D. Cui, S. L. Wu, C. F. Li, S. L. Zhu, and X. J. Yang, "Corrosion behavior of oil tube steels under conditions of multiphase flow saturated with super-critical carbon dioxide," Materials Letters, vol. 58, no. 6, pp. 1035-1040, 2004.

[13] M. Cabrini, S. Lorenzi, T. Pastore, and M. Redaelli, "Corrosion rate of carbon steel in condensed water and humid gas at high $\mathrm{CO}_{2}$ pressure," in Proceedings of the European Corrosion Congress (EUROCORR '13), Estoril, Portugal, September 2013.

[14] M. Cabrini, S. Lorenzi, T. Pastore, and M. Radaelli, "Corrosion rate of high $\mathrm{CO}_{2}$ pressure pipeline steel for carbon capture transport and storage," La Metallurgia Italiana, vol. 106, no. 6, pp. 21-27, 2014.

[15] S. Nešić and K.-L. J. Lee, "A mechanistic model for carbon dioxide corrosion of mild steel in the presence of protective iron carbonate films - part 3: film growth model," Corrosion, vol. 59, no. 7, pp. 616-628, 2003.

[16] S. Nešić, M. Nordsveen, R. Nyborg, and A. Stangeland, "A mechanistic model for carbon dioxide corrosion of mild steel in the presence of protective iron carbonate films-part 2: a numerical experiment," Corrosion, vol. 59, no. 6, pp. 489-497, 2003.

[17] R. D. Braun, "Solubility of iron(II) carbonate at temperatures between 30 and $80^{\circ}$," Talanta, vol. 38, no. 2, pp. 205-211, 1991.

[18] J. Han, D. Young, H. Colijn, A. Tripathi, and S. Nešić, "Chemistry and structure of the passive film on mild steel in $\mathrm{CO}_{2}$ corrosion environments," Industrial and Engineering Chemistry Research, vol. 48, no. 13, pp. 6296-6302, 2009.

[19] W. Li, B. Brown, D. Young, and S. Nesic, "Investigation of pseudo-passivation on mild steel in $\mathrm{CO}_{2}$ corrosion," Corrosion Science, vol. 70, no. 3, pp. 294-302, 2014. 

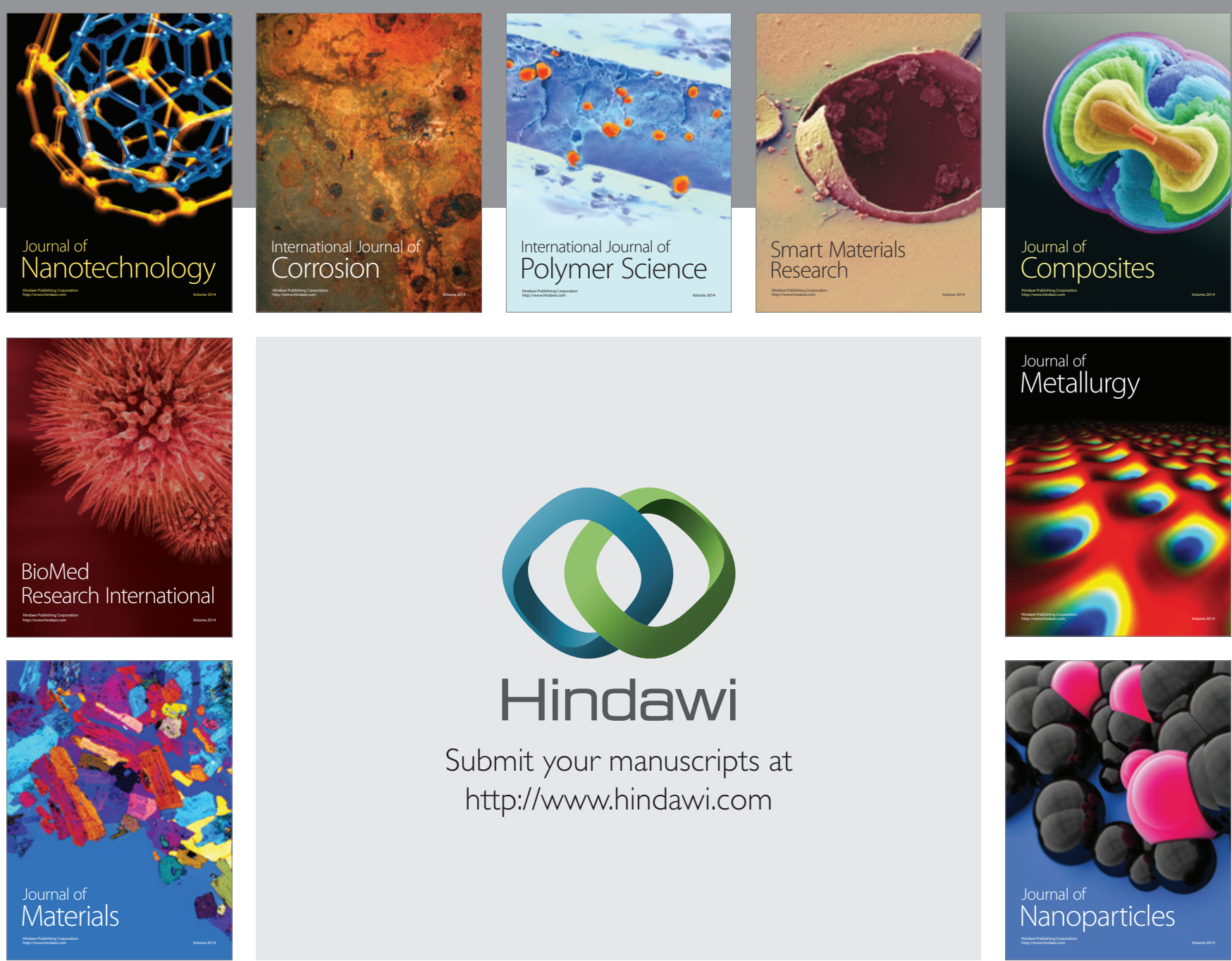

\section{Hindawi}

Submit your manuscripts at

http://www.hindawi.com

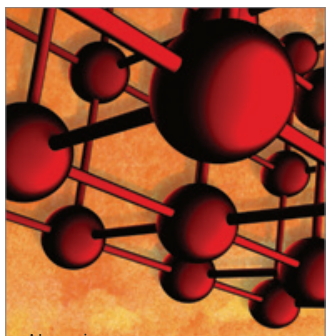

Materials Science and Engineering
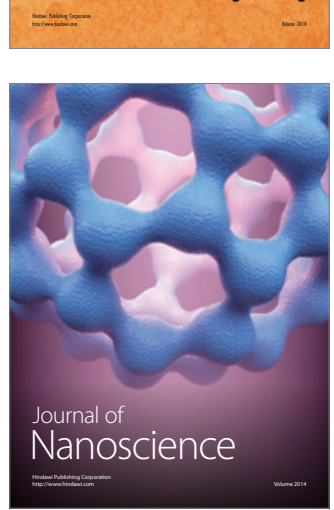
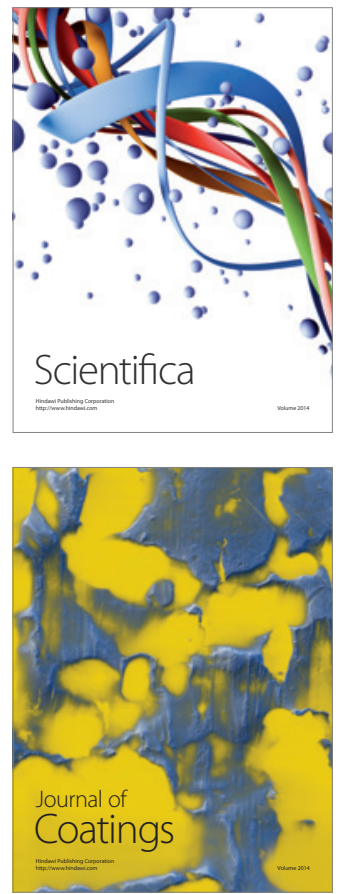
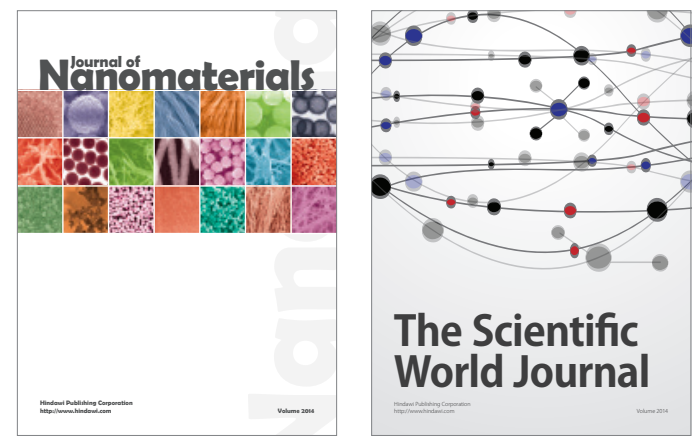

The Scientific World Journal
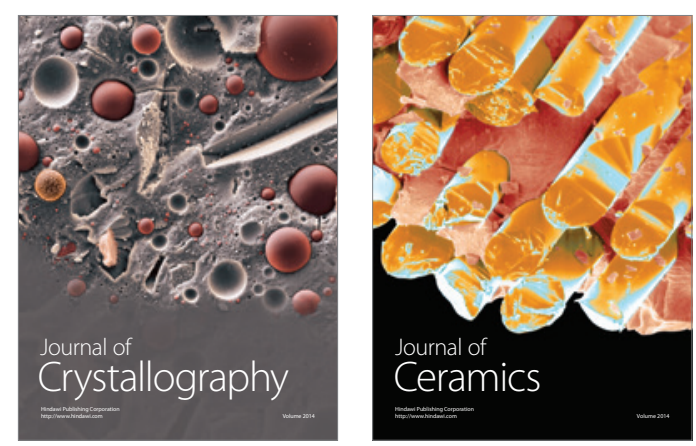
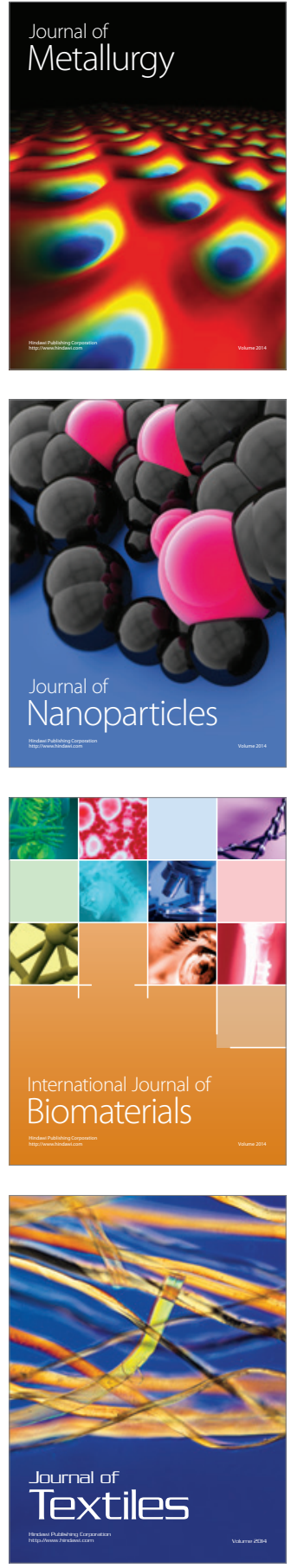